\title{
Viagem à Luta Armada: entre a ficção e a história
}

Marina Ruivo* 
Viagem à Luta Armada, de Carlos Eugênio Paz - narrando sua vivência guerrilheira do fim dos anos 1960 ao início dos 70 -, pode ser caracterizado como pertencente à literatura de testemunho, pelo entrecruzamento de documento de um período da história brasileira com a narrativa literária (Cf. BOSI, 1995). Seu compromisso é duplo: com a história e com a ficção. Aquele verifica-se quando o narrador contrapõe-se a outros intérpretes dos acontecimentos:

"Começamos a trabalhar febrilmente. Desminto os que tentam menosprezar nossa atuação militar. Assaltamos com sucesso vários bancos, tomamos o primeiro Brink's deste país, realizamos operações com até quinze combatentes, fechamos quarteirões para atacar mais de um objetivo, e o assalto ao Banco do Brasil, no Jabaquara, é uma amostra do que podíamos realizar com apenas uma semana de levantamento e planejamento, e uma execução primorosa, onde as falhas não existiram. $\mathrm{O}$ seqüestro do embaixador alemão, com a participação de Célio e o comando de Rafael, que foram ao Rio para a ação, em frente com a VR, foi outro exemplo de que não éramos tão despreparados como alguns intérpretes equivocados ou mal-intencionados procuram nos apresentar. Quando tudo for História, os que viveram intensamente esses momentos terão a palavra, será difícil tergiversar. Estaremos lá para desmentir, para afirmar. Perdoem a demora, é que todos somos sentimentais, é difícil dar a vida de outra forma" (PAZ, 1996, p. 59). 
O texto oferece ainda outras passagens em que se procura dar sua versão de ator do ocorrido, o que é perceptível pelo próprio conjunto da obra, o qual aborda episódios centrais e controversos da história da ALN (Ação Libertadora Nacional). Há também muitos traços reveladores da presença da ficção. De imediato, pensemos no fato de que as pessoas reais que viveram o narrado não aparecem denominadas por seus próprios nomes. Muitas vezes, parece que o autor adotou um dos vários codinomes utilizados pelos guerrilheiros, mas esse não é o único procedimento. O caso da denominação de Silvério para o traidor que levou à morte de Diogo é sintomático de que houve uma clara intencionalidade ficcional já na seleção dos nomes.

A história da ALN é contada através da narração em primeira pessoa, o que marca a ficcionalização da experiência no combate. Essa história, presentificada - os verbos estão sempre no presente -, não segue uma trajetória linear e cronológica. Ao contrário, são narrados episódios da guerrilha, revelando o cotidiano das ações em detalhes, destacando os sonhos, os sentimentos, o companheirismo, o medo, o cansaço, a coragem, a cumplicidade, a ternura. O tempo da guerrilha engloba não só ações militares, mas os relacionamentos de Clamart, suas amizades e amores. Destes, a paixão por Marcela e o relacionamento com ela ganham especial destaque. Marcela é a mulher de Clamart, guerrilheira corajosa, sensível, bela. O relacionamento deles é abordado diversas vezes, e suas idas e vindas pontuam a narrativa, demarcam momentos. Marcela desempenha um papel tão relevante que podemos pensar que ela estrutura a narrativa da guerrilha: marcam-se os momentos antes de conhecê-la, o período do amor secreto, o período em que se amaram, as discussões e desentendimentos, o término.

Como Marcela, Felipe, Poeta, Fabiano, Diogo, Rafael, num outro plano, ocupam tal força que se tornam personagens. Não se trata mais de Ana Maria Nacinovic, ou Alex de Paula Xavier Pereira, Aldo Sá Brito, Carlos Marighella, Joaquim Câmara Ferreira, ou Eduardo Colem Leite de carne e osso, mas de como foram vividos por Clamart (que não é Carlos Eugênio Paz, pois também foi ficcionalizado), como ficaram em sua memória e como foram reconstruídos. A narrativa da primeira vez em que viu Marcela já coloca-a no plano da ficção: "Marcela entra sorrindo no carro e em minha vida, bela como nenhuma outra, paixão ao primeiro ponto. Proibida, ela é 
companheira de Assad, sonharei com ela e a desejarei em segredo, não tenho o direito de interferir no amor dos dois.” (PAZ, 1996, p. 146)

A narrativa da guerrilha é rica ficcionalmente, revivendo a época em seus valores próprios. Retratar o cotidiano da ALN é significativo para aproximar a obra ao romance, gênero que busca apreender o real particular (Cf. WATT, 1996, p. 31). O período da guerrilha, pontuado por mortes e infortúnios, é vivido com enorme carga de utopia e, no balanço geral a que procede a obra, prevalece a consideração positiva, traço particularizador deste livro no conjunto dos outros depoimentos de ex-guerrilheiros. Nele tenta-se compreender as entranhas da luta armada, situando o passado como fonte criadora do presente.

Paralela à narrativa da guerrilha descortina-se outra, de Clamart após a luta. É essa história que abre o livro, com o narrador-personagem em seu banheiro (no exílio em Paris), vomitando após injetar heroína e compondo um "quadro repugnante" (p. 15). Cena emblemática, que guarda um dos significados centrais da obra e que traz o ex-guerrilheiro ao plano dos mortais, retirando-o do elevado que nós leitores poderíamos colocá-lo. O pósluta armada contrasta com o período anterior, no qual Clamart está em constante movimento, realizando ações espetaculares e tocando o universo da aventura.

Mergulhado no escuro de sua banheira, sozinho e sem contato com o mundo exterior, Clamart perde o sentido de sua vida. Finda a guerrilha, que infelizmente não venceu a feroz ditadura militar, este homem imerge na banheira e submerge em sua existência, o que se percebe não propriamente, ou não apenas, pelo consumo de drogas, mas pela incapacidade de agir no presente, de criar uma nova forma de vida. Ainda que busque refugiar-se no presente, sua vida é a recordação de um passado com o qual possui uma relação contraditória: desejaria apagá-lo por completo, esquecê-lo, para viver o presente livre de fantasmas, mas é o próprio passado que lhe preenche a vida. É no passado, justamente, que este eu encontrará a chave que lhe permitirá encarar a vida, presente, passada e futura.

Entretanto o presente, que beira a estagnação, não se resume à cena inicial, mas retorna constantemente no livro, percorrendo uma trajetória. A banheira é uma "banheira uterina, espécie de túnel úmido e quente, onde tudo é permitido.” (p. 16), um intervalo, um local de passagem em que o 
narrador-personagem prepara o nascimento de uma nova vida, a qual não nascerá sozinha, pois necessita conseguir relacionar-se de novo com as pessoas e lidar com seu passado sem a culpa por estar vivo. Narrando os preparativos da ação de assalto ao cinema, na iniciação à guerrilha, sua fala a Aureliano é extremamente significativa: "- Agora é guerrilha urbana de verdade, Aureliano, até a vitória ou a morte, como o Che.” (p. 96) Ou seria a vitória - que não houve -, ou a morte, que não veio. Sobreviver só fazia sentido se fosse rumo à vitória, não com a derrota. Viver para a luta era o mais importante, e a alegria em escapar do cerco policial no primeiro episódio de ação do livro - “como é bom viver...” (p. 21) - contrasta com sua constatação no pós-luta: "Aprendi a sobreviver, não me serve de nada, não sei viver.” (pp. 79-80) É preciso expurgar a culpa, reencontrar sentido em estar vivo, e ele percebe que necessita de auxílio: "Preciso de ajuda... real fora do túnel... real, fora do túnel real... fora do... não consigo sair daqui... será isso loucura? Será isso loucura?' (p. 49)

No desenrolar da leitura, do movimento da guerrilha à estagnação da banheira, percebe-se que este eu iniciou uma terapia. Sendo um livro de testemunho da guerrilha, é importante considerar como o autor representa não apenas a época de luta, mas a posterior busca de reconstrução do seu ser, fazendo da terapeuta mais uma personagem. As sessões são focalizadas de modo fragmentário - lentamente percebe-se o caminhar deste eu -, incluindo seus diálogos. Há inclusive uma referência metalingüística ao próprio livro que estamos lendo: Helena, a terapeuta, pergunta sobre ele e a resposta é: “- Escrevo penosamente, choro, as palavras saem aos trancos, é um vômito. Nem sei se tem algum valor, mas não é possível parar, vou até o fim, seja o que for. Por enquanto são histórias soltas, me falta um fio para costurá-las." (p. 155) Aqui se revela quão emblemática era a cena inicial do livro, quando o narrador-personagem vomita. $\mathrm{O}$ vômito põe para fora o que não pode mais ficar dentro, o que prejudica. Para criar uma nova vida, a partir do passado, é preciso colocá-lo para fora.

Isso se faz de duas maneiras complementares: primeiramente, pela palavra oral, narrando suas histórias a Helena, o que lhe permite voltar ao convívio social. Nessa narração, o ex-guerrilheiro tem de dizer tudo, acontecimentos suaves e alegres e, principalmente, o que o engasga. Em rodeios, narra a morte de Poeta, compreendida como sendo um novo ciclo em sua 
vida. Encarando a morte de Poeta, encara o episódio mais obscuro da ALN: o justiçamento de Mário, da Coordenação Nacional, numa decisão de Clamart, Marcela, Hermes e Célio, mais por temor que por suspeita de traição. Dos quatro que tomaram a decisão, só Clamart sobreviveu, fazendo com que o peso sobre ele aumente: só ele pode contar a versão da ALN e dizer o que foi e porque. Narrando este episódio polêmico, revela o sentido de compromisso com a história (Cf. PAZ, 1996, p.206).

A outra forma de resgatar o passado e expurgar a culpa é a escrita. Escrevendo reorganiza sua experiência e compartilha-a com um público virtual infinito. Não apenas rompe o isolamento, mas se reconstitui plenamente, pois cria uma nova missão: é portador de uma experiência e vai narrá-la a quem não a viveu, para despertar reflexões, especialmente nas novas gerações. Narrar é catarse, única possibilidade de criação de vida. Clamart torna-se um narrador, guardião da memória social brasileira, ao menos de um pedaço importante dela. Tendo sobrevivido e compartilhado essa experiência, que não é só sua, mas também de seus companheiros, ele permite que estes vivam: “(...) e vozes sem rosto sussurram em meus sonhos: ‘Que bom que está vivo, vivemos em você...” (p. 184)

Dá, à experiência que viveu, o "acabamento", nos termos de Hannah Arendt, para que não se perca o "tesouro" vivenciado, a beleza e amargor daqueles anos, seus acertos e erros (ARENDT, 1979). Faz seu ajuste de contas com a experiência e a história, para criar-se uma nova vida. Por isso que é do passado que provém a força de seu reerguer-se. Narrando o que viveu e viu, tirando a força da narrativa das mortes que vivenciou, torna-se um narrador, no sentido de Walter Benjamin. Narrar é "intercambiar experiências" (1996).

Viagem à Luta Armada, como estréia literária de Carlos Eugênio Paz, afirma seu duplo compromisso, com a história e com a ficção, inserindo-se na história da sociedade e da literatura brasileira. 


\section{REFERÊNCIAS BIBLIOGRÁFICAS}

ARENDT, Hannah. "A Quebra entre o Passado e o Futuro", in: Entre o passado e o futuro. [trad.: Mauro W. Barbosa de Almeida]. 2 $2^{\mathrm{a}}$ ed. São Paulo: Perspectiva, 1979, pp. 28-42. BENJAMIN, Walter. "O narrador (Considerações sobre a obra de Nikolai Leskov)”, in: Obras Escolhidas, Vol. 1, Magia e Técnica, Arte e Política - Ensaios sobre Literatura e História da Cultura. [trad: Sergio Paulo Rouanet]. $7^{\mathrm{a}}$ ed./10 $0^{\mathrm{a}}$ reimp. São Paulo: Brasiliense, 1996, pp. 197-221.

BOSI, Alfredo. “A escrita do testemunho em Memórias do Cárcere”, in: Estudos Avançados. São Paulo, IEA/USP, Vol. 9, no 23, jan./abril de 1995, pp. 309-322.

PAZ, Carlos Eugênio. Viagem à Luta Armada: memórias romanceadas. $2^{\mathrm{a}}$ ed. Rio de Janeiro: Civilização Brasileira, 1996.

WATT, Ian. A ascensão do romance: estudos sobre Defoe, Richardson e Fielding. [trad.: Hildegard Feist]. $1^{\underline{a}}$ reimp. São Paulo: Companhia das Letras, 1996. 
